\title{
Vascular Endothelial Injury and Apoptosis in Rats with Severe Acute Pancreatitis
}

\author{
Ning Ge, ${ }^{1}$ Qing Xia, ${ }^{2}$ Zhong-Hua Yang, ${ }^{1}$ Qun-Fang Ding, ${ }^{1}$ and Zhi Zeng ${ }^{3}$ \\ ${ }^{1}$ Division of Geriatric Medicine, West China Hospital of Sichuan University, Chengdu, Sichuan 610041, China \\ ${ }^{2}$ Chinese Medicine Department, West China Hospital of Sichuan University, Chengdu, Sichuan 610041, China \\ ${ }^{3}$ Cardiac Medicine Department, West China Hospital of Sichuan University, Chengdu, Sichuan 610041, China
}

Correspondence should be addressed to Zhi Zeng; grace7733@163.com

Received 12 October 2014; Accepted 5 January 2015

Academic Editor: Maria Eugenicos

Copyright (c) 2015 Ning Ge et al. This is an open access article distributed under the Creative Commons Attribution License, which permits unrestricted use, distribution, and reproduction in any medium, provided the original work is properly cited.

\begin{abstract}
We explored mechanisms of vascular endothelial injury that lead to systemic multiple organ failure by detecting the soluble endothelial protein $\mathrm{C}$ receptor (sEPCR), von Willebrand factor (vWF), serum nitric oxide (NO), and tumor necrosis factor alpha (TNF- $\alpha$ ) and Bcl-2 mRNA and Bax mRNA expression in a severe acute pancreatitis (SAP) rat model. Compared to controls, the levels of TNF- $\alpha$, vWF, and sEPCR were significantly increased in the experimental group at 12 hours and 24 hours and the NO level was significantly decreased. After 12 hours, the aortic endothelial apoptosis index and Bax mRNA expression in aortic endothelial cells had increased in the experimental group, but Bcl-2 mRNA levels had decreased. All these changes appeared at both $12 \mathrm{~h}$ and 24 hours. The results indicated that vascular endothelial injury and apoptosis markers were elevated in SAP. Endothelial injury and increased apoptosis in the experimental group were related to the increased expression of TNF- $\alpha$.
\end{abstract}

\section{Introduction}

Severe acute pancreatitis (SAP) progresses rapidly, often induces systemic multiple organ failure, and has a mortality rate between 10 and $30 \%$. Scientists originally thought that increased trypsin activity triggered acute pancreatitis and hypothesized that SAP developed when pancreatic enzymes were released into the circulatory system [1]. Because trypsin inhibitors did not successfully prevent or reverse the effects of SAP [2], further research was performed and the progression of acute pancreatitis to SAP has recently been linked to pancreatic microvascular spasm, changes in hemodynamics, and the excessive activation of inflammatory mediators [2], possibly by hemorrhagic changes [3-6].

The specific mechanisms of circulation disturbance in SAP remain unclear. In order to delineate these mechanisms, we measured the amount of pathological injury to the pancreas and the levels of tumor necrosis factor- $\alpha$ (TNF- $\alpha$ ), von Willebrand factor (vWF), soluble endothelial protein C receptor (sEPCR), serum nitric oxide (NO), and Bcl-2 mRNA and Bax mRNA in the blood of a rat model of SAP.

\section{Materials and Methods}

The study protocol was approved by the Animal Care Committee of West China Hospital of Sichuan University. A total of 48 two- to three-month-old Sprague-Dawley (S-D) rats that weighed between 180 and $200 \mathrm{~g}$ were randomly divided into a control group and an experimental group. After surgery, 12 rats in each group were sacrificed at 12 hours and 12 were sacrificed at 24 hours, making four groups of 12 animals each.

The rats were housed six to a cage at room temperature on a $12: 12$ light/dark cycle with free access to food and water for five days before the study. Food, but not water, was withdrawn 12 hours before the study started.

The rats were anesthetized with $2 \%$ ketamine $(80 \mathrm{mg} / \mathrm{kg})$ injected into the intraperitoneal cavity. SAP was produced in the experimental group by two injections of an $8 \%$ solution of L-arginine ( $\mathrm{pH} 7.0$, Sigma Co., USA) $(4.4 \mathrm{mg} / \mathrm{g}$ of body weight, administered intraperitoneal cavity) given one hour apart $[7,8]$. The control group received two injections of an equal amount of $0.9 \%$ normal saline. 
Twelve rats from each group were sacrificed under anesthesia $12 \mathrm{~h}$ and $24 \mathrm{~h}$ after the injections. Blood samples were taken and centrifuged for $10 \mathrm{~min}$ at 3,000 rpm. The serum was preserved at $-80^{\circ} \mathrm{C}$. The aorta was removed and preserved at $-70^{\circ} \mathrm{C}$ after being frozen in liquid nitrogen for PCR analysis. Part of the aorta was fixed with $4 \%$ formalin and embedded in paraffin sections for a TUNEL test.

Tissue extracted from the head of the pancreas was fixed with a $40 \mathrm{~g} / \mathrm{L}$ formalin solution, paraffin-embedded, sliced, and stained with hematoxylin and eosin ( $\mathrm{HE})$. A pathologist examined the tissue and gave it a pathology score according to the Kusske standard [9] based on edema, cell inflammation, and necrosis. ELISA was used to measure sEPCR, vWF, $\mathrm{NO}$, and TNF- $\alpha$. A reverse transcriptase polymerase chain reaction study (RT-PCR) was performed according to the manufacturer's instructions. Aortic endothelial apoptosis was detected with a TA200 In Situ Apoptosis Detection Kit (R\&D Co., USA).

2.1. Statistical Analysis. Results from in vitro studies are expressed as mean $\pm \mathrm{SD}$. After a homogeneity test of variance, a comparison between the means of two samples was made using two $t$-tests of group design.

\section{Results}

Pancreatic tissue from the control group revealed no edema or inflammatory cell infiltration at any time point (Table 1). In the experimental group, there were partial pancreatic tissue necrosis and gland structure disappearance at $12 \mathrm{~h}$, along with red-stained, nonstructural material formation and a large amount of inflammatory cell infiltration and bleeding. The glands that were not necrotic were edematous. After 24 hours, the pancreatic acinar structure of the rats in the experimental group had disappeared and congestive edema was visible between the cells and the acinar lobules. A small amount of inflammatory cell infiltration was occasionally observed (Figure 1).

After $12 \mathrm{~h}$, the levels of vWF, sEPCR, and TNF- $\alpha$ were significantly increased in the experimental group compared to the control group $(1.12 \pm 0.17$ versus $0.531 \pm 0.22, P<0.05$; $3.749 \pm 0.27$ versus $2.254 \pm 0.175, P<0.05$; and $70.452 \pm 2.927$ versus $25.28 \pm 1.420, P<0.05$, resp.) (Table 2$)$. These levels were the same at $24 \mathrm{~h}$. The $\mathrm{NO}$ level in the experimental group was significantly lower than the $\mathrm{NO}$ level in the control group at $12 \mathrm{~h}(2.729 \pm 0.613$ versus $5.121 \pm 1.562, P<0.05)$, and this discrepancy was also observed at $24 \mathrm{~h}$ (Table 2 ).

The pancreatic pathological score in the experimental group was significantly increased compared to the control group at $12 \mathrm{~h}(6.77 \pm 1.37$ versus $3.67 \pm 0.817, P<0.05)$ and remained at this level at $24 \mathrm{~h}$ (Table 2 ).

There were only a few apoptotic cells in the aortic endothelia of the control group at $12 \mathrm{~h}$, but the number of these cells in the experimental group was significantly higher at $12 \mathrm{~h}$ and remained higher at $24 \mathrm{~h}(51.47 \pm 23.56$ versus $5.87 \pm$ $0.15, P<0.01$ ) (Figure 3, Table 2). The experimental group had significantly less Bcl-2 mRNA expression (0.00224 \pm 0.00049 versus $0.00985 \pm 0.0039, P<0.05)$ and significantly more Bax mRNA expression (0.00897 \pm 0.0036 versus
TABLE 1: Pathological score standard.

\begin{tabular}{llc}
\hline Index & Classification standards & Score \\
\hline \multirow{3}{*}{ Edema } & Interlobular local edema & 1 \\
& Interlobular diffuse edema & 2 \\
& Gland disorder, separation & 3 \\
\hline Inflammatory cells & No & 0 \\
\hline \multirow{5}{*}{ Infiltration } & No & 0 \\
& Confined to the catheter & 1 \\
& Limited to the parenchyma $(<50 \%)$ & 2 \\
& Limited to the parenchyma $(>50 \%)$ & 3 \\
\hline \multirow{5}{*}{ Acinar necrosis } & No & 0 \\
& Necrosis around the catheter $(<5 \%)$ & 1 \\
& Focal necrosis $(5 \% \sim 20 \%)$ & 2 \\
& Substantial diffuse necrosis $(>20 \%)$ & 3 \\
\hline
\end{tabular}

$0.00184 \pm 0.00051, P<0.05)$ than the control group at $12 \mathrm{~h}$, and this was also true at $24 \mathrm{~h}$. The $\mathrm{Bcl}-2 / \mathrm{Bax}$ mRNA ratio was lower in the experimental group than the control group $(P<0.05)$ at both 12 and $24 \mathrm{~h}$ (Figure 2$).$

\section{Discussion}

Despite a great deal of basic science research, the exact mechanism of SAP remains unknown. Treatment is mostly ineffective, and the SAP mortality rate remains high at 10$30 \%$. Many researchers attribute multiorgan failure in SAP to a combination of primary pancreatic enzyme activation and pancreatic autodigestion, followed by secondary immunemediated damage and the breakdown of vascular barriers. Vascular endothelial cell injury and functional changes may be the core mechanism of circulatory disturbances in SAP; but whether vascular endothelial injury actually exists in SAP and whether this injury triggers multiorgan failure have not been extensively researched.

We chose a classic rat SAP model to observe changes in the serological markers of arterial endothelial injury and endothelial apoptosis. We also explored whether the mechanism of vascular endothelial injury and apoptosis in SAP is associated with increased TNF- $\alpha$ expression.

Rising sEPCR and vWF concentrations in plasma are a sign of vascular endothelial cell injury. vWF has strong sensitivity but lacks specificity because levels fluctuate with mild stimulation $[10,11]$. sEPCR maintains a stable concentration, does not change with age, and is not affected by mild stimulation [12-15]. Together, these two markers can accurately measure endothelial cell trauma.

The vWF and sEPCR levels in our experimental group were significantly higher than the levels in the control group at both $12 \mathrm{~h}$ and $24 \mathrm{~h}(P<0.05)$. This suggests that SAP injured the vascular endothelial cells and the degree of injury rose as the condition progressed. We think that both vWF and sEPCR can be used to determine the severity of SAP and formulate a probable prognosis.

Causes of endothelial cell injury in SAP are complicated and may be associated with a number of factors. One factor 


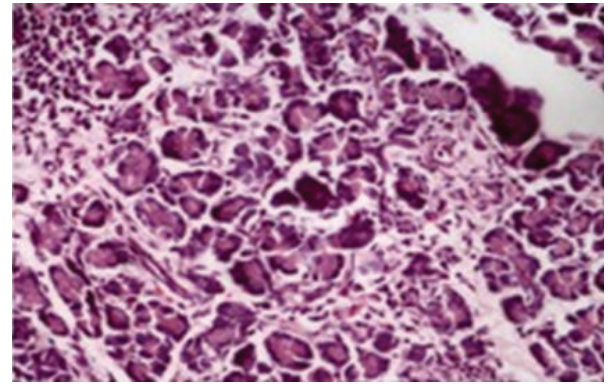

(a) Control group $-12 \mathrm{~h}$

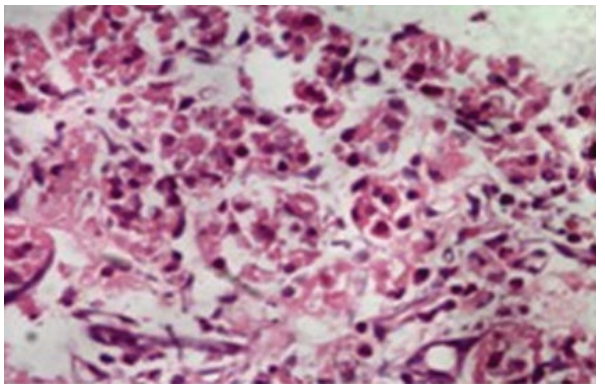

(c) Experimental group-12 h

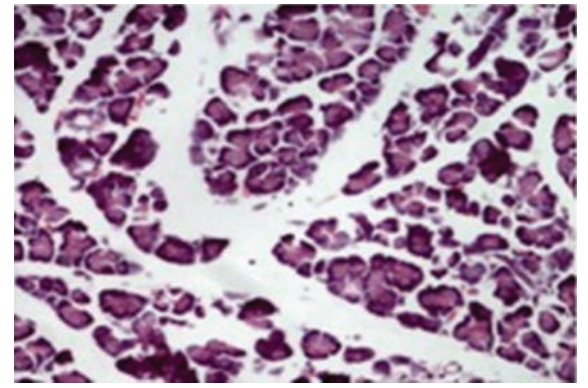

(b) Control group $-24 \mathrm{~h}$

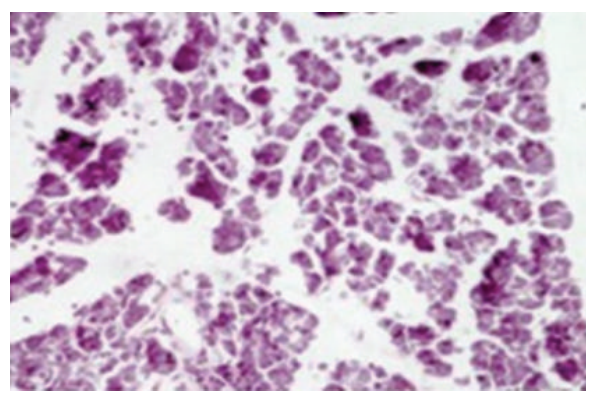

(d) Experimental group-24h

Figure 1: Pancreatic tissue HE staining.

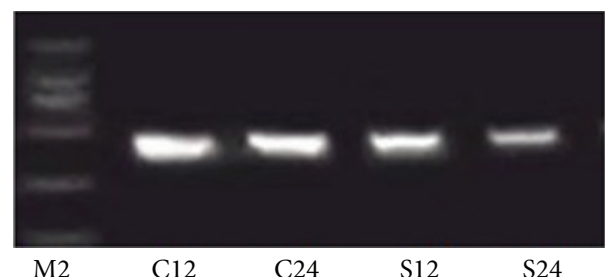

(a)

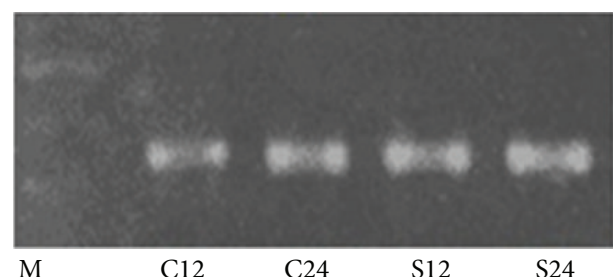

(b)

Figure 2: (a) BCL-2 and (b) Bax RT-PCR analysis of the aortic endothelium in the experimental and control groups after 12 hours and 24 hours.

TABLE 2: Expression level of vWF, sEPCR, NO, and TNA- $\alpha$.

\begin{tabular}{|c|c|c|c|c|}
\hline & \multicolumn{2}{|c|}{ Control group } & \multicolumn{2}{|c|}{ SAP group } \\
\hline & $12 \mathrm{~h}$ & $24 \mathrm{~h}$ & $12 \mathrm{~h}$ & $24 \mathrm{~h}$ \\
\hline vWF & $0.531 \pm 0.22$ & $0.544 \pm 0.2603$ & $1.12 \pm 0.17$ & $1.2475 \pm 0.13$ \\
\hline$P$ & & & $<0.05$ & $<0.05$ \\
\hline sEPCR & $2.254 \pm 0.175$ & $2.2477 \pm 0.175$ & $3.749 \pm 0.27$ & $4.132 \pm 0.140$ \\
\hline$P$ & & & $<0.05$ & $<0.05$ \\
\hline NO & $5.121 \pm 1.562$ & $5.105 \pm 0.856$ & $2.729 \pm 0.613$ & $2.258 \pm 0.144$ \\
\hline$P$ & & & $<0.05$ & $<0.05$ \\
\hline TNF- $\alpha$ & $25.28 \pm 1.420$ & $24.031 \pm 10.42$ & $70.452 \pm 2.927$ & $93.260 \pm 18.431$ \\
\hline$P$ & & & $<0.01$ & $<0.01$ \\
\hline Pathological store & $3.67 \pm 0.817$ & $3.67 \pm 0.817$ & $6.77 \pm 1.37$ & $8.53 \pm 1.26$ \\
\hline$P$ & & & $<0.05$ & $<0.05$ \\
\hline $\mathrm{Al}$ & $5.87 \pm 0.15$ & $11.04 \pm 0.56$ & $51.47 \pm 23.56$ & $68.03 \pm 12.51$ \\
\hline$P$ & & & $<0.01$ & $<0.01$ \\
\hline
\end{tabular}




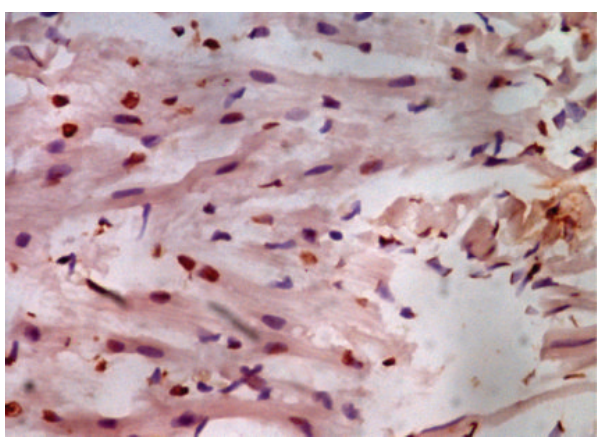

(a)

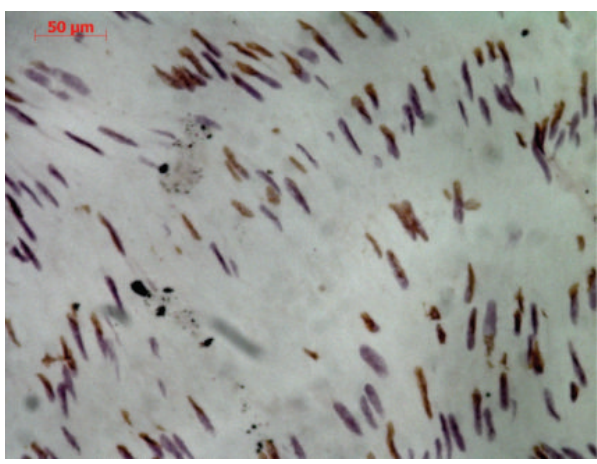

(c)

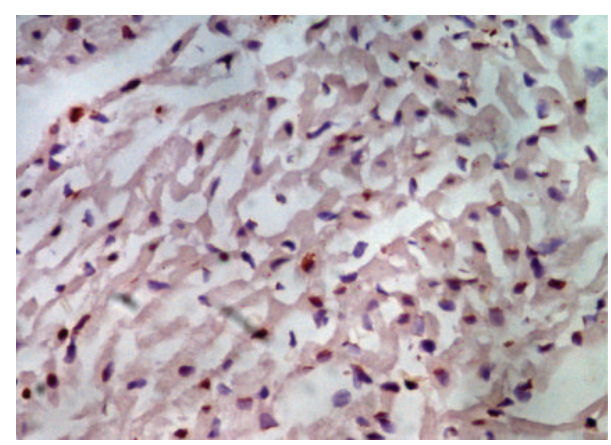

(b)

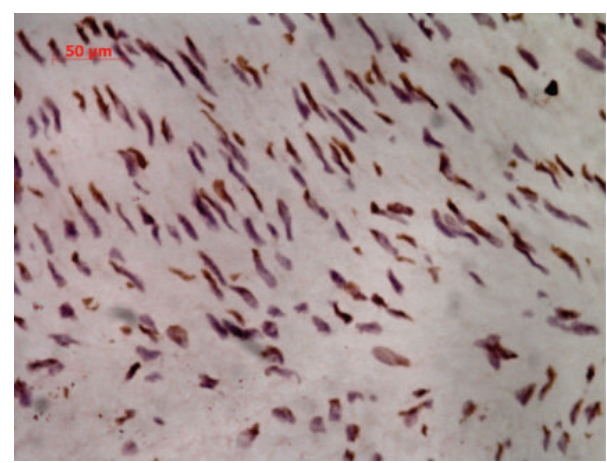

(d)

FIgURE 3: Aortic endothelial cell apoptosis TUNEL analysis results. (a), (b) Aortic endothelial cell apoptosis in the control group after $12 \mathrm{~h}$ (a) and $24 \mathrm{~h}$ (b). (c), (d) Aortic endothelial cell apoptosis in the experimental group after $12 \mathrm{~h}$ (c) and $24 \mathrm{~h}$ (d).

is oxidative stress. Activated endothelial cells produce large amounts of reactive oxygen species that cause oxidative damage and dysfunction in the endothelium unless they are scavenged and removed from the system [16]. SAP interferes with this scavenging and removal. Activated endothelial cells also produce select adhesion molecules that release cytokines that damage the endothelium [17-20]. Endothelin (ET) is produced in massive quantities in acute pancreatitis and increases as the disease progresses. When the ratio of ET to $\mathrm{NO}$ is not balanced, peripheral resistance in the circulatory system increases and elevates the blood pressure. Elevated blood pressure aggravates endothelial cell injury [21]. The pancreas releases many enzymes during SAP that accelerate pancreatic gland necrosis and travel through the circulation to damage vascular endothelial cells as well.

In recent years, research has focused on the relationship between cell factors, such as tumor necrosis factor- $\alpha$ (TNF$\alpha$ ) and SAP. TNF- $\alpha$ is a cytokine produced by mononuclear macrophages that has a very wide range of biological activity. TNF receptors exist on the vascular endothelial surface and research according to [22] suggests that TNF- $\alpha$ has a direct cytotoxic effect on vascular endothelial cells [23].

At $12 \mathrm{~h}$, the serum TNF- $\alpha$ concentration in our experimental group was significantly higher than that of the control group $(P<0.05)$, and as the TNF- $\alpha$ concentration rose so did the rats' vascular endothelial injury factor. Both concentrations continued to rise and reached their highest levels at $24 \mathrm{~h}$.

We concluded that TNF- $\alpha$ played an important role in arterial endothelial injury in our SAP rat model. In this study, we were not sure about the causality between the tumor necrosis factor and vascular endothelial injury; previous researches have confirmed the tumor necrosis factor through the four aspects of the mechanism damage of vascular endothelium. Four factors may contribute to the mechanism. First, TNF- $\alpha$ can cause direct damage [24]. Second, TNF$\alpha$ can activate the lysosomal enzyme complex and increase cell surface protease expression, which further damages endothelial cells $[25,26]$. Third, TNF- $\alpha$ can significantly promote platelet growth and release. A high platelet count signals injury in the body, and this signal attracts monocytes that transform into macrophages to clean up cellular debris. Large amounts of TNF- $\alpha$ are released in the process, creating more injury that attracts more monocytes and damages the vascular endothelium in a repetitive loop. Fourth, the increased expression of TNF- $\alpha$ increases the permeability of vascular endothelial cells, resulting in vascular endothelial dysfunction $[27,28]$.

$\mathrm{Bcl}-2$ family proteins are the regulators of apoptosis; this family of interacting partners includes inhibitors and inducers of cell death. Together they regulate and mediate the process by which mitochondria contribute to cell death known as the intrinsic apoptosis pathway [29]. Bcl-2 and Bax are important apoptosis regulatory genes of $\mathrm{Bcl}-2$ family. The overexpression of Bcl-2 inhibits apoptosis and the overexpression of Bax accelerates apoptosis [30-33]. In our study, aortic endothelial cell apoptosis was significantly increased in the experimental group after 12 hours and continued to increase up to 24 hours. Controls had only small amounts of 
aortic endothelial cell apoptosis and there was a significant difference between the apoptosis indexes of the two groups $(P<0.05)$. Bcl-2 mRNA expression had decreased significantly and Bax mRNA expression had increased significantly $24 \mathrm{~h}$ after SAP was induced. The Bcl-2/Bax mRNA ratio was lower in the experimental group than in the control group at $12 \mathrm{~h}$ and continued to drop until $24 \mathrm{~h}(P<0.05)$.

These results suggest that aortic endothelial cell apoptosis in rats with SAP is associated with alterations in the Bcl2/Bax mRNA expression ratio, which is supported by other researches [33]. Endothelial cell apoptosis in SAP rats was related to increased serum TNF- $\alpha$. In our study, we did not determine the aetiological relation between endothelial cell apoptosis and TNF- $\alpha$; previous researches demonstrated that TNF- $\alpha$ induces endothelial cell apoptosis by calcium overload, lipid peroxidation, and the function of the redox imbalance [34-36]. In addition, a large number of cytotoxicfree oxygen radicals were produced that caused endothelial damage and cell apoptosis [37].

\section{Conclusions}

Vascular endothelial injury markers and Bax markers of vascular endothelial apoptosis increased in SAP, but Bcl-2 markers of vascular endothelial apoptosis decreased. This indicates that multiple organ failure in SAP is associated with direct damage to the pancreas as well as circulatory disturbances, and endothelial injury and increased apoptosis are associated with the increased expression of TNF- $\alpha$.

\section{Conflict of Interests}

The authors declare that there is no conflict of interests regarding the publication of this paper.

\section{Authors' Contribution}

Ning Ge and Zhi Zeng conceived and designed the experiments. Qun-Fang Ding and Zhong-Hua Yang performed the experiments. Ning Ge and Qing Xia analyzed the data. Ning Ge wrote the paper. Ning Ge and Zhi Zeng contributed equally to this work.

\section{Acknowledgment}

This work was supported by grants from the Science and Technology Support Projects of Sichuan Technology and Science Department for (2011SZ0122).

\section{References}

[1] R. M. S. Mitchell, M. F. Byrne, and J. Baillie, "Pancreatitis," The Lancet, vol. 361, no. 9367, pp. 1447-1455, 2003.

[2] J. Slavin, P. Ghaneh, R. Sutton et al., "Management of necrotizing pancreatitis," World Journal of Gastroenterology, vol. 7, no. 4, pp. 476-481, 2001.

[3] T. Kyogoku, T. Manabe, and T. Tobe, "Role of ischemia in acute pancreatitis. Hemorrhagic shock converts edematous pancreatitis to hemorrhagic pancreatitis in rats," Digestive Diseases and Sciences, vol. 37, no. 9, pp. 1409-1417, 1992.
[4] X. B. Liu, L. N. Yan, and Z. D. Zhang, "Association between acute pancreatitis and hemarheology," Journal of West China University of Medical Sciences, vol. 28, pp. 218-221, 1997.

[5] E. Q. Mao, S. D. Zhang, and T. Q. Han, "Pancreatic ischemia: a continuous injury factor in acute necrotic pancreatitis," Chinese Journal of Surgery, vol. 35, no. 3, pp. 150-152, 1997.

[6] L. N. Yan, H. G. Wu, and H. Q. Chen, "The change and significance of hemorrheologic alternation in experimental acute necrotizing pancreatitis," Chinese Journal of Digest, vol. 10, pp. 32-34, 1990 .

[7] Z. Rakonczay Jr., P. Hegyi, S. Dósa et al., "A new severe acute necrotizing pancreatitis model induced by l-ornithine in rats," Critical Care Medicine, vol. 36, no. 7, pp. 2117-2127, 2008.

[8] A. Szabolcs, R. J. Reiter, T. Letoha et al., "Effect of melatonin on the severity of L-arginine-induced experimental acute pancreatitis in rats," World Journal of Gastroenterology, vol. 12, no. 2, pp. 251-258, 2006.

[9] A. M. Kusske, A. J. Rongione, S. W. Ashley, D. W. McFadden, and H. A. Reber, "Interleukin-10 prevents death in lethal necrotizing pancreatitis in mice," Surgery, vol. 120, no. 2, pp. 284-289, 1996.

[10] R. E. Ware, R. I. Parker, L. P. McKeown, and M. L. Graham, "A human chimera for von Willebrand disease following bone marrow transplantation," American Journal of Pediatric Hematology/Oncology, vol. 15, no. 3, pp. 338-342, 1993.

[11] A. D. Blaxm and D. A. Taberner, "A reliable marker of endothelial cell dysfimction: does it exist?" British Journal of Haematology, vol. 90, pp. 244-248, 1995.

[12] K. Fukudome and C. T. Esmon, "Identification, cloning, and regulation of a novel endothelial cell protein $\mathrm{C}$ activated protein C receptor," Journal of Biological Chemistry, vol. 269, no. 42, pp. 26486-26491, 1994.

[13] D. J. Stearns-Kurosawa, S. Kurosawa, J. S. Mollica, G. L. Ferrell, and C. T. Esmon, "The endothelial cell protein $\mathrm{C}$ receptor augments protein $\mathrm{C}$ activation by the thrombin-thrombomodulin complex," Proceedings of the National Academy of Sciences of the United States of America, vol. 93, no. 19, pp. 10212-10216, 1996.

[14] C. T. Esmon, J. Xu, J.-M. Gu et al., "Endothelial protein C receptor," Thrombosis and Haemostasis, vol. 82, no. 2, pp. 251258, 1999.

[15] K. Fukudome, X. Ye, N. Tsuneyoshi et al., "Activation mechanism of anticoagulant protein $\mathrm{C}$ in large blood vessels involving the endothelial cell protein C receptor," The Journal of Experimental Medicine, vol. 187, no. 7, pp. 1029-1035, 1998.

[16] N. Kobayashi, K. Yoshida, S. Nakano et al., "Cardioprotective mechanisms of eplerenone on cardiac performance and remodeling in failing rat hearts," Hypertension, vol. 47, no. 4, pp. 671679, 2006.

[17] R. Kacimi, J. S. Karliner, F. Koudssi, and C. S. Long, "Expression and regulation of adhesion molecules in cardiac cells by cytokines response to acute hypoxia," Circulation Research, vol. 82, no. 5, pp. 576-586, 1998.

[18] G. L. J. Dixon, R. S. Heyderman, P. Van Der Ley, and N. J. Klein, "High-level endothelial E-selectin (CD62E) cell adhesion molecule expression by a lipopolysaccharide-deficient strain of Neisseria meningitidis despite poor activation of NF- $\kappa \mathrm{B}$ transcription factor," Clinical and Experimental Immunology, vol. 135, no. 1, pp. 85-93, 2004.

[19] R. Kacimi, J. S. Karliner, F. Koudssi, and C. S. Long, "Expression and regulation of adhesion molecules in cardiac cells by cytokines: response to acute hypoxia," Circulation Research, vol. 82, no. 5, pp. 576-586, 1998. 
[20] J. G. Wagner and R. A. Roth, "Neutrophil migration mechanisms, with an emphasis on the pulmonary vasculature," Pharmacological Reviews, vol. 52, no. 3, pp. 349-374, 2000.

[21] G. X. Wang and Y. Liu, "Vascular endothelial cell damage mechanism and progress of drug protection," Journal of Liaoning Medical University, vol. 29, no. 5, pp. 466-468, 2008.

[22] P. P. Nawroth and D. M. Stern, "Modulation of endothelial cell hemostatic properties by tumor necrosis factor," The Journal of Experimental Medicine, vol. 163, no. 3, pp. 740-745, 1986.

[23] J. Brett, H. Gerlach, P. Nawroth, S. Steinberg, G. Godman, and D. Stern, "Tumor necrosis factor/cachectin increases permeability of endothelial cell monolayers by a mechanism involving regulatory G proteins," Journal of Experimental Medicine, vol. 169, no. 6, pp. 1977-1991, 1989.

[24] V. W. M. van Hinsbergh, T. Kooistra, E. A. van den Berg, H. M. G. Princen, W. Fiers, and J. J. Emeis, "Tumor necrosis factor increases the production of plasminogen activator inhibitor in human endothelial cells in vitro and in rats in vivo," Blood, vol. 72, no. 5, pp. 1467-1473, 1988.

[25] K. Vaddi, F. A. Nicolini, P. Mehta, and J. L. Mehta, "Increased secretion of tumor necrosis factor-alpha and interferon-gamma by mononuclear leukocytes in patients with ischemic heart disease: relevance in superoxide anion generation," Circulation, vol. 90, no. 2, pp. 694-699, 1994.

[26] A. L. Doiron, A. P. Kirkpatrick, and K. D. Rinker, "TGF$\beta$ and TNF- $\alpha$ affect cell surface proteoglycan and sialic acid expression on vascular endothelial cells," Biomedical Sciences Instrumentation, vol. 40, pp. 331-336, 2004.

[27] Q. Shi, J. Wang, X. L. Wang, and J. L. VandeBerg, "Comparative analysis of vascular endothelial cell activation by TNF- $\alpha$ and LPS in humans and baboons," Cell Biochemistry and Biophysics, vol. 40, no. 3, pp. 289-303, 2004.

[28] D. Meng and N. Liu, "Expression of platelet-endothelial cell adhesion molecule-1 in human umbilical vein endothelial cells by exposure to advanced glycosylation end products and inflammatory mediators," Chinese Medical Journal, vol. 116, no. 9, pp. 1336-1340, 2003.

[29] J. Marie Hardwick and L. Soane, "Multiple functions of BCL-2 family proteins," Cold Spring Harbor Perspectives in Biology, vol. 5, no. 2, 2013.

[30] J. Neuzil, X.-F. Wang, L.-F. Dong, P. Low, and S. J. Ralph, "Molecular mechanism of 'mitocan'-induced apoptosis in cancer cells epitomizes the multiple roles of reactive oxygen species and Bcl2 family proteins," FEBS Letters, vol. 580, no. 22, pp. 5125-5129, 2006.

[31] D. M. Hockenbery, Z. N. Oltvai, X.-M. Yin, C. L. Milliman, and S. J. Korsmeyer, "Bcl-2 functions in an antioxidant pathway to prevent apoptosis," Cell, vol. 75, no. 2, pp. 241-251, 1993.

[32] T. Ohmori, E. R. Podack, K. Nishio et al., "Apoptosis of lung cancer cells caused by some anticancer agents is inhibited by Bcl-2," Biochemical and Biophysical Research Communications, vol. 192, no. 1, pp. 30-36, 1993.

[33] X.-X. Duan, J.-S. Ou, Y. Li et al., "Dynamic expression of apoptosis-related genes during development of laboratory hepatocellular carcinoma and its relation to apoptosis," World Journal of Gastroenterology, vol. 11, no. 30, pp. 4740-4744, 2005.

[34] N. Makino, T. Maeda, M. Sugano, S. Satoh, R. Watanabe, and N. Abe, "High serum TNF- $\alpha$ level in Type 2 diabetic patients with microangiopathy is associated with eNOS down-regulation and apoptosis in endothelial cells," Journal of Diabetes and its Complications, vol. 19, no. 6, pp. 347-355, 2005.
[35] C. J. Rhodes, “Type 2 diabetes-a matter of beta cell life and death?” Science, vol. 307, no. 5708, pp. 380-384, 2005.

[36] K. A. Krown, M. T. Page, C. Nguyen et al., "Tumor necrosis factor alpha-induced apoptosis in cardiac myocytes. Involvement of the sphingolipid signaling cascade in cardiac cell death," Journal of Clinical Investigation, vol. 98, no. 12, pp. 2854-2865, 1996.

[37] S. J. Korsmeyer, "Bcl-2 initiates a new category of oncogenes: regulators of cell death," Blood, vol. 80, no. 4, pp. 879-886, 1992. 


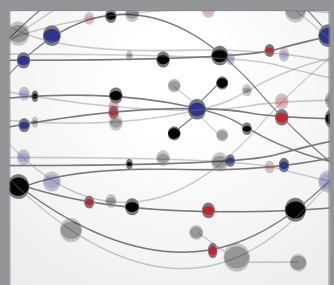

The Scientific World Journal
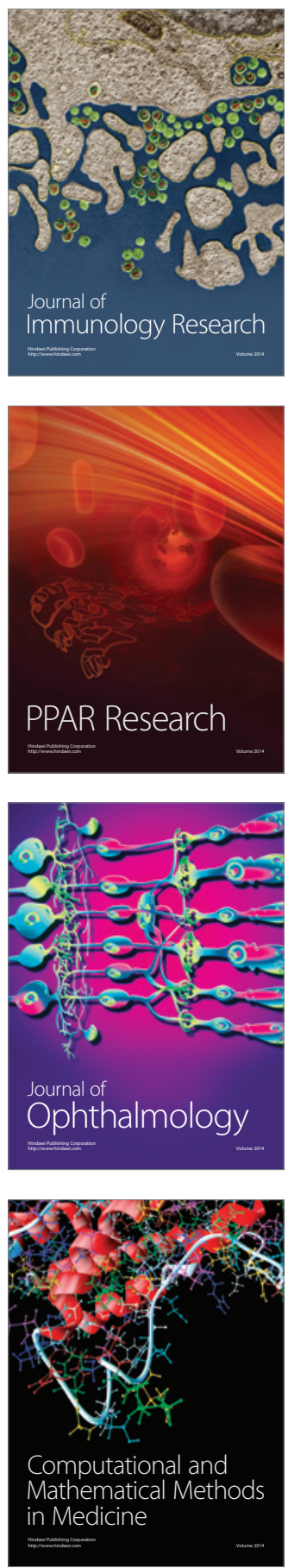

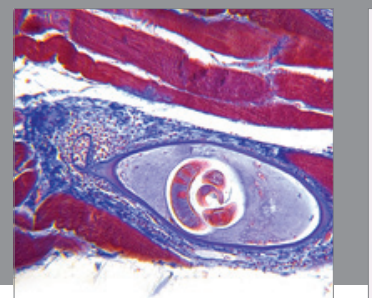

Gastroenterology

Research and Practice
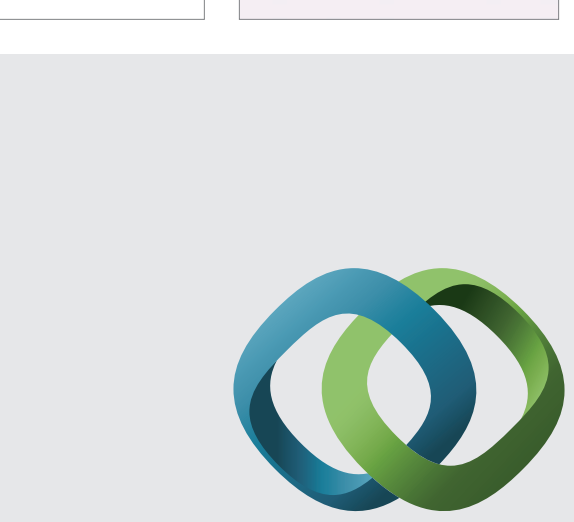

\section{Hindawi}

Submit your manuscripts at

http://www.hindawi.com
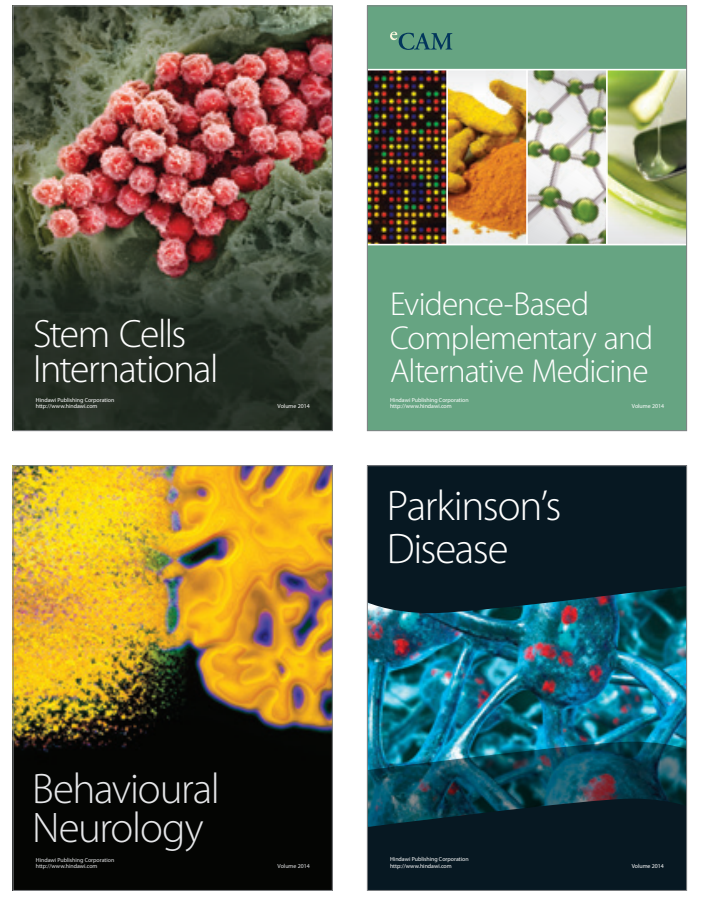
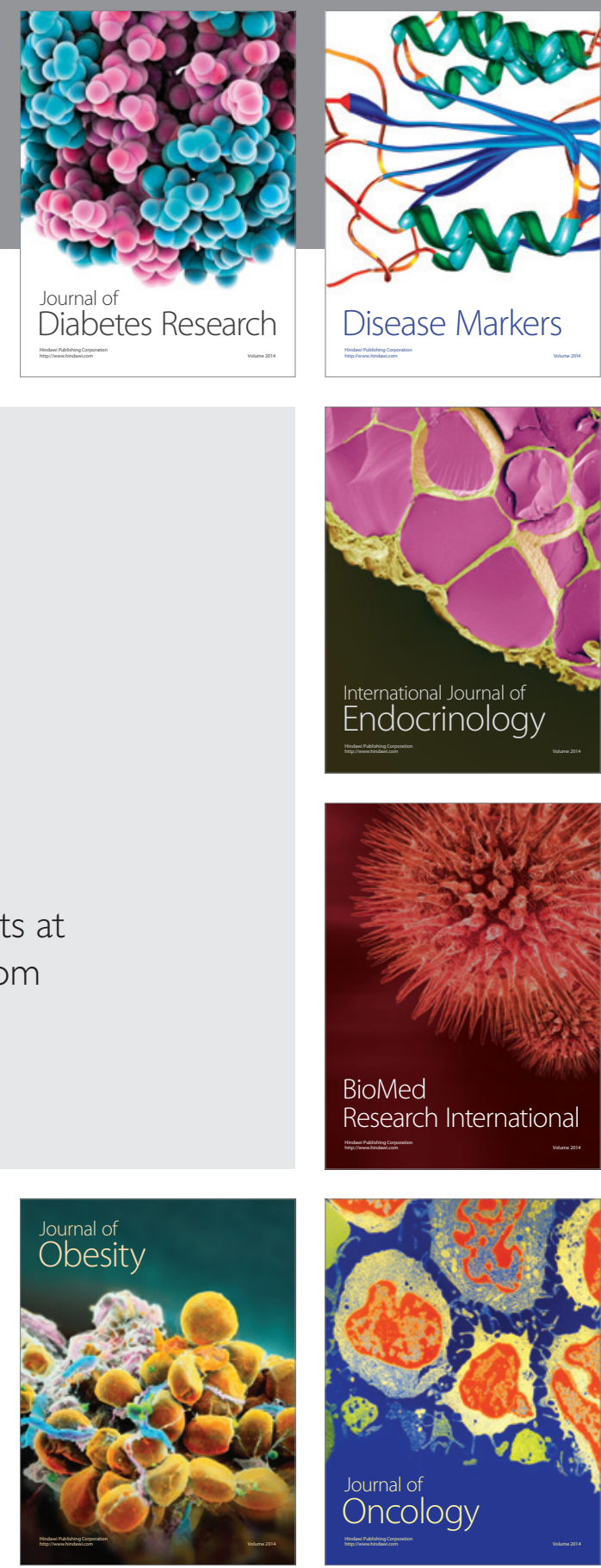

Disease Markers
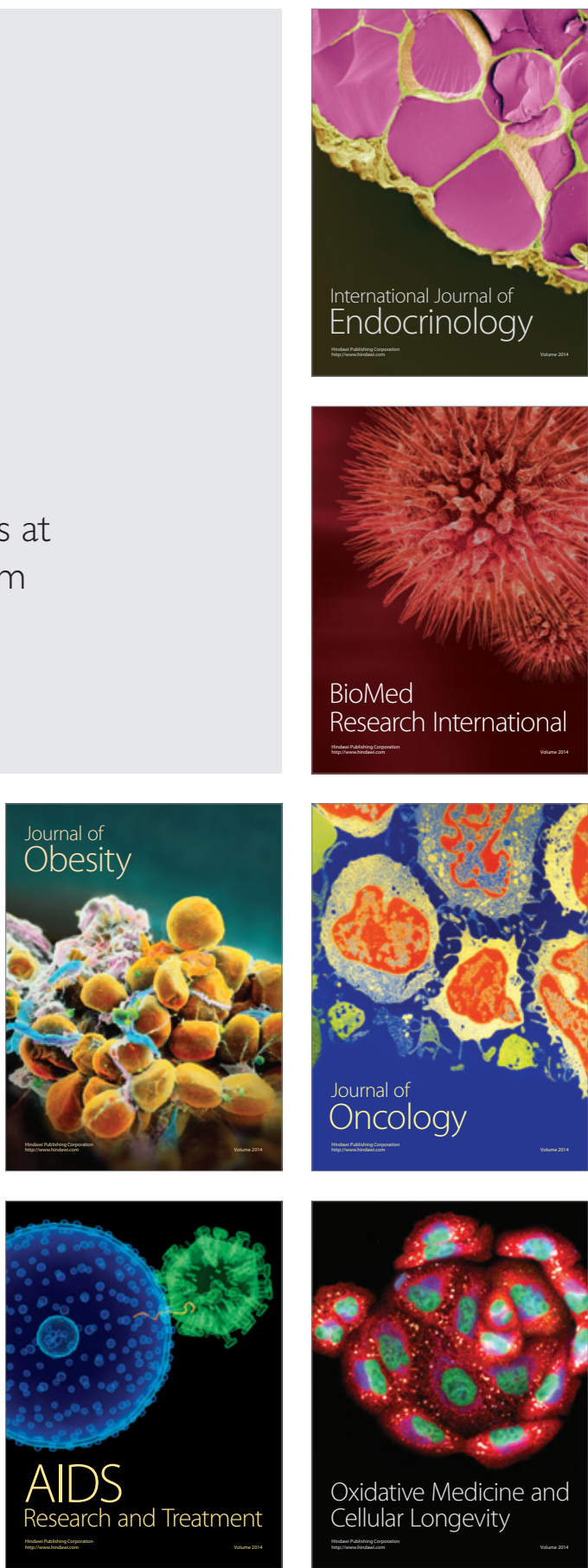